\title{
ВЛАГОСОДЕРЖАНИЕ ПРИРОДНОГО ГАЗА В ПРИЗАБОЙНОЙ ЗОНЕ ПЛАСТА
}

\author{
Э.А.БОНДАРЕВ, И.И.РОЖИН, К.К.АРГУНОВА \\ ФГБУН «Институт проблем нефти и газа Сибирского отделения РАН», Якутск, Россия
}

Для модельной задачи отбора реального газа из скважины в центре кругового пласта с непроницаемыми кровлей и подошвой выполнен анализ влияния начальных пластовых условий на динамику распределения его влагосодержания. Использовалась математическая модель неизотермической фильтрации, в которой теплопроводность считалась пренебрежимо малой по сравнению с конвективным переносом. Для ее замыкания использовалась эмпирическая зависимость коэффициента несовершенства газа от давления и температуры, апробированная в предыдущих публикациях авторов. Связь между влагосодержанием, давлением и температурой газа описывалась эмпирическими зависимостями, основанными на формуле Бюкачека. Вычислительный эксперимент выполнялся следующим образом. Вначале из численного решения осесимметричной задачи неизотермической фильтрации реального газа определись давление и температура газа при заданном давлении на забое скважины. При этом условия на внешней границе пласта имитировали водонапорный режим отбора газа. Затем эти найденные функции времени и координат использовались для вычисления аналогичной зависимости для влагосодержания. Результаты эксперимента показали, что если пластовая температура существенно превышает равновесную температуру гидратообразования, то распределение влагосодержания в призабойной зоне будет практически идентично распределению температуры. В противном случае газ будет содержать пары воды только вблизи забоя скважины, а далее его влагосодержание будет практически равно нулю. Роль давления и в том и в другом случаях проявляется через интенсивность отбора газа, от которого, в свою очередь, зависят и интенсивность конвективного переноса тепла, и степень охлаждения газа за счет дросселирования.

Ключевые слова: влагосодержание природных газов; неизотермическая фильтрация; газовые гидраты; вычислительный эксперимент

Как цитировать эту статью: Бондарев Э.А. Влагосодержание природного газа в призабойной зоне пласта / Э.А.Бондарев, И.И.Рожин, К.К.Аргунова // Записки Горного института. 2018. Т. 233. С. $492-497$. DOI: 10.31897/PMI.2018.5.492

Введение. В недавней публикации авторов [1] описаны особенности добычи природного газа в Арктической зоне России, которые необходимо учитывать при математическом моделировании соответствующих технологических процессов. В ней же были приведены многочисленные примеры расчета образования газовых гидратов в скважинах и магистральных газопроводах. Настоящая публикация призвана дополнить статью [1] анализом динамики температуры и давления в призабойной зоне газовых скважин и оценкой влияния этих технологических параметров на влагосодержание добываемого газа. Актуальность решения такой задачи определяется тем воздействием, которое оказывает пластовая вода на гидратообразование в призабойной зоне, а также необходимостью осушки газа перед его подачей в магистральный газопровод. Кроме того, при существующей практике закачки в скважины метанола или других ингибиторов для предотвращения гидратообразования непосредственно в газоносном пласте необходимо предварительно вычислять расход этого реагента.

Равновесное влагосодержание природного газа. В пластах-коллекторах газовых и газоконденсатных месторождений газ контактирует с остаточной пластовой водой либо с краевыми и подстилающими водами и, следовательно, содержит пары воды. В условиях термодинамического равновесия их максимальное количество зависит от давления, температуры и состава газа [3-5, 7, 9]. Оно называется влагосодержанием $w$ и в термодинамике определяется как отношение массы водяного пара $m_{\mathrm{H}_{2} \mathrm{O}}$ к массе сухого газа $m_{\mathrm{g}}$. В инженерных расчетах из-за подражания переводным справочникам США в России под влагосодержанием понимается отношение массы водяных паров к приведенному к стандартным условиям объему сухого газа $W$ в килограммах на $1000 \mathrm{~m}^{3}$.

Аналитические зависимости влагосодержания природных газов $W$ от давления $p$ в паскалях и температуры $T$ являются модификациями формулы Бюкачека [13]:

$$
W=\frac{A(T)}{p}+B(T),
$$

где $A$ - коэффициент, равный влагоемкости (влагосодержание в условиях насыщения) идеального газа при нормальном атмосферном давлении; $B$ - поправка на неидеальность природного газа, зависящая от состава газа $[4,7]$. 
Остановим свой выбор на соотношениях, предложенных в монографиях $[3,4]$ как наиболее употребительных:

$$
\begin{aligned}
W G(p, T) & =10^{-3}\left(\frac{0,457}{p} \exp \left(0,0735(T-273,15)-0,00027(T-273,15)^{2}\right)\right)+ \\
& +0,0418 \exp \left(0,054(T-273,15)-0,0002(T-273,15)^{2}\right) ; \\
& W B(p, T)=0,016 \cdot 10^{-3}\left(\frac{0,1 p s(T)}{p} 47482+10^{-\frac{1713,3}{T}+6,694}\right),
\end{aligned}
$$

где $p s(T)=0,0061038 \exp \left(0,0735(T-273,15)-0,00027(T-273,15)^{2}\right)$ - давление водяных паров над чистой водой.

Соотношения (2), (3) рекомендуется использовать для природных газов с относительной плотностью по воздуху 0,6 . Их идентичность демонстрирует рис.1. В дальнейших расчетах использовалась формула (3), так как ее легко модифицировать в случае, когда надо вычислять давление паров воды в газовой фазе, равновесной с гидратом. При этом вместо функции $p s(T)$ следует воспользоваться соответствующим эмпирическим соотношением, в качестве которого нами выбрана формула, предложенная в работе [4]:

$$
p_{\mathrm{H}_{2} \mathrm{O}}^{\mathrm{h}}(p, T)=\exp \left(29,396-\frac{6234,874}{T}-0,1593 \ln (p)\right) .
$$

Динамика влагосодержания в призабойной зоне газовых скважин. Влагосодержание, согласно соотношению (3), является функцией давления и температуры. Следовательно, чтобы определить характер ее распределения в призабойной зоне пласта, необходимо решить задачу неизотермической фильтрации реального газа при соответствующих граничных и начальных условиях.

Для математического описания отбора газа через одиночную скважину, расположенную в центре круговой залежи, воспользуемся системой уравнений, описывающей неизотермическую фильтрацию реального газа в пористой среде, в которой перенос энергии за счет теплопроводности считается пренебрежимо малым по сравнению с конвективным переносом $[2,11,12]$. Сведем исходные уравнения неизотермической фильтрации в осесимметричной постановке к безразмерным уравнениям относительно давления и температуры газа:

$$
\begin{gathered}
\frac{\partial}{\partial \bar{t}}\left(\frac{\bar{p}}{\mathrm{Z} \bar{T}}\right)=\frac{1}{\bar{r}} \frac{\partial}{\partial \bar{r}}\left(\bar{r} \frac{\bar{p}}{\mathrm{Z} \bar{T}} \frac{\partial \bar{p}}{\partial \bar{r}}\right), \bar{r}_{\mathrm{b}}<\bar{r}<\bar{r}_{\mathrm{k}}, \bar{t}>0 ; \\
\frac{\partial \bar{T}}{\partial \bar{t}}=\left(1+\frac{\bar{T}}{\mathrm{Z}} \frac{\partial \mathrm{Z}}{\partial \bar{T}}\right) \frac{\partial \bar{p}}{\partial \bar{t}}+\frac{c_{p}}{R} \frac{\bar{p}}{\mathrm{Z} \bar{T}} \frac{\partial \bar{T}}{\partial \bar{r}} \frac{\partial \bar{p}}{\partial \bar{r}}-\frac{\bar{T}}{\mathrm{Z}} \frac{\partial \mathrm{Z}}{\partial \bar{T}}\left(\frac{\partial \bar{p}}{\partial \bar{r}}\right)^{2}, \bar{r}_{\mathrm{b}}<\bar{r}<\bar{r}_{\mathrm{k}}, \bar{t}>0 ;
\end{gathered}
$$

где $\quad \bar{t}=\kappa_{p} t / l^{2} ; \quad \bar{p}=p / p_{0} ; \quad \bar{T}=c_{\mathrm{r}} T / m p_{0} ;$ $\bar{r}=r / l ; \quad \bar{r}_{\mathrm{b}}=r_{\mathrm{b}} / l ; \quad \bar{r}_{\mathrm{k}}=r_{\mathrm{k}} / l ; c_{p}-$ удельная теплоемкость газа при постоянном давлении; $c_{\mathrm{r}}$ - объемная теплоемкость газонасыщенной пористой среды; $k$ - коэффициент проницаемости; $l$ - характерный размер; $m$ - пористость; $p$ - давление; $R$ - газовая постоянная; $r$ - радиальная координата; $r_{\mathrm{b}}-$ наружный радиус скважины; $r_{\mathrm{k}}-$ радиус контура пласта; $T$ - температура; $t$ - время; $\mathrm{Z}$ - коэффициент несовершенства газа; $\kappa_{p}$ коэффициент пьезопроводности газонасыщенной пористой среды, $\kappa_{p}=k p_{0} / m \eta ; \eta-$ динамическая вязкость газа; нижний индекс

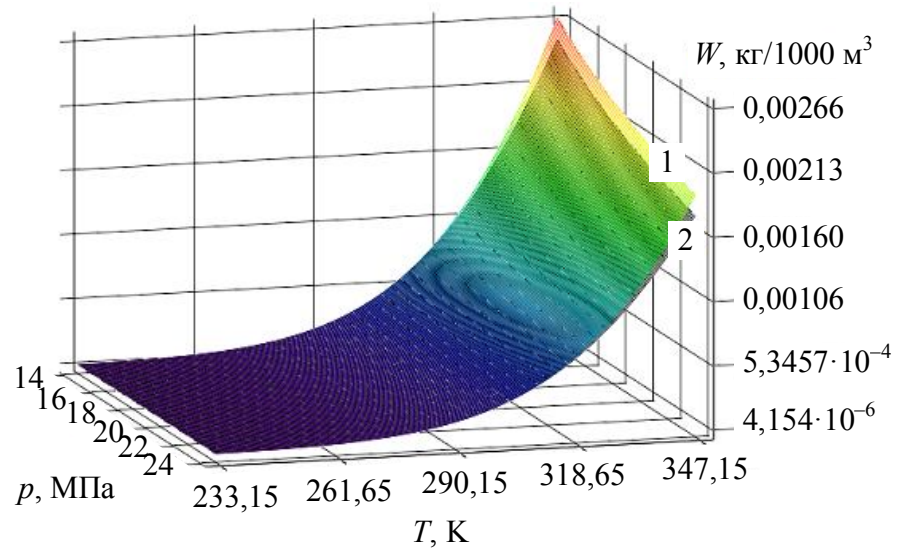

Рис.1. Зависимость влагосодержания природного газа от температуры и давления. Поверхность 1 построена по формуле (3), поверхность 2 - по формуле (2) 
«0» соответствует начальному состоянию газоносного пласта. В дальнейшем черта над безразмерными переменными для удобства опускается.

В работе [10] показано, что с точки зрения технологии добычи режим отбора с постоянным давлением на забое скважины наиболее благоприятен, так как он обеспечивает более равномерное распределение давления по сравнению с режимом постоянного дебита. Тем самым на забое скважины задается постоянное давление газа

$$
p=p_{\mathrm{b}} ; \quad r=r_{\mathrm{b}} .
$$

На контуре питания задаются условия, моделирующие отсутствие потоков фильтрующегося газа и тепла, т.е. описывается водонапорный режим отбора газа:

$$
\frac{\partial p}{\partial r}=0 ; \quad \frac{\partial T}{\partial r}=0 ; \quad r=r_{\mathrm{k}} .
$$

В начальный момент времени давление и температура считаются постоянными:

$$
p(r, 0)=1 ; \quad T(r, 0)=T_{0} ; \quad r_{\mathrm{b}} \leq r \leq r_{\mathrm{k}} .
$$

Следует отметить, что в данной постановке температура газа на забое скважины (при $r=r_{\mathrm{b}}$ ) является искомой величиной, определяемой в ходе решения задачи, а уравнение (6) - квазилинейным гиперболическим уравнением первого порядка. Характеристики данного уравнения выходят из правой границы, поэтому граничного условия отсутствия теплового потока (8) достаточно для определения его единственного решения.

В качестве уравнения состояния принимается уравнение Латонова - Гуревича [8]

$$
\mathrm{Z}=\left(0,17376 \ln \left(\frac{m p_{0}}{c_{\mathrm{r}} T_{\mathrm{c}}} T\right)+0,73\right)^{\frac{p_{0}}{p_{\mathrm{c}}} p}+0,1 \frac{p_{0}}{p_{\mathrm{c}}} p,
$$

где нижний индекс «с» соответствует критическому состоянию природного газа, который представляет собой смесь газов, в основном, парафинового ряда, начиная с метана.

Критические давление и температура газовой смеси определяются по правилу Кейа [14]:

$$
p_{\mathrm{c}}=\sum_{i=1}^{n} y_{i} p_{\mathrm{c} i} ; T_{\mathrm{c}}=\sum_{i=1}^{n} y_{i} T_{\mathrm{c} i},
$$

где $y_{i}, p_{\mathrm{c} i}, T_{\mathrm{c} i}$ - объемная доля, критические давление и температура $i$-го компонента природного газа.

Газовая постоянная газовой смеси определяется по формуле

$$
R=8,314 / \mu_{g},
$$

где $\mu_{g}=\sum_{i=1}^{n} y_{i} \mu_{g i}-$ молярная масса природного газа; $\mu_{g i}-$ молекулярный вес $i$-го компонента природного газа.

Расчеты выполнялись при следующих значениях параметров, соответствующих двум месторождениям Республики Саха (Якутия). 1. Средневилюйское: $R=449,4$ Дж/(кг $\cdot \mathrm{K}) ; p_{0}=24$ МПа; $T_{0}=323 \mathrm{~K} ; \quad p_{\mathrm{b}}=14 \mathrm{M \Pi а} ; \quad p_{\mathrm{c}}=4,6596 \mathrm{M \Pi а} ; \quad T_{\mathrm{c}}=205,022 \mathrm{~K} ; \quad c_{p} / R=5,118 ; \quad c_{\mathrm{r}} / m p_{0}=1,2341 / \mathrm{K} ;$ $a=7,009 \mathrm{~K}$ и $b=178,28 \mathrm{~K}$ - константы для вычисления равновесной температуры гидратообразования, найдены путем аппроксимации кривой термодинамического равновесия, определяемой по методике Слоана [15] или по методике Истомина [6] при известном составе газа (объемные доли), \%: $\mathrm{CH}_{4} 90,34 ; \quad \mathrm{C}_{2} \mathrm{H}_{6} 4,98 ; \quad \mathrm{C}_{3} \mathrm{H}_{8} 1,74 ; \quad i \mathrm{C}_{4} \mathrm{H}_{10} 0,22 ; \quad n \mathrm{C}_{4} \mathrm{H}_{10} 0,41 ; \quad \mathrm{C}_{5} \mathrm{H}_{12+} 1,55$; $\mathrm{CO}_{2} 0,28 ; \mathrm{N}_{2} 0,48 ;$ плотность газа по воздуху $-0,634$.

2. Отраднинское: $\quad R=438,3$ Дж/(кг $\cdot \mathrm{K}) ; \quad p_{0}=18,835 \mathrm{MПа} ; \quad T_{0}=286,35 \mathrm{~K} ; \quad p_{\mathrm{b}}=16,87 \mathrm{MПа}$; $p_{\mathrm{c}}=4,471 \mathrm{MПа;} T_{\mathrm{c}}=195,376 \mathrm{~K} ; c_{p} / R=5,248 ; c_{\mathrm{r}} / m p_{0}=3,5391 / \mathrm{K} ; a=6,635 \mathrm{~K} ; b=182,951 \mathrm{~K} ;$ состав газа (объемные доли), \%: $\mathrm{CH}_{4} 83,15 ; \quad \mathrm{C}_{2} \mathrm{H}_{6} 4,16 ; \quad \mathrm{C}_{3} \mathrm{H}_{8} 1,48 ; \quad i \mathrm{C}_{4} \mathrm{H}_{10} 0,17 ; \quad n \mathrm{C}_{4} \mathrm{H}_{10} 0,50$; 

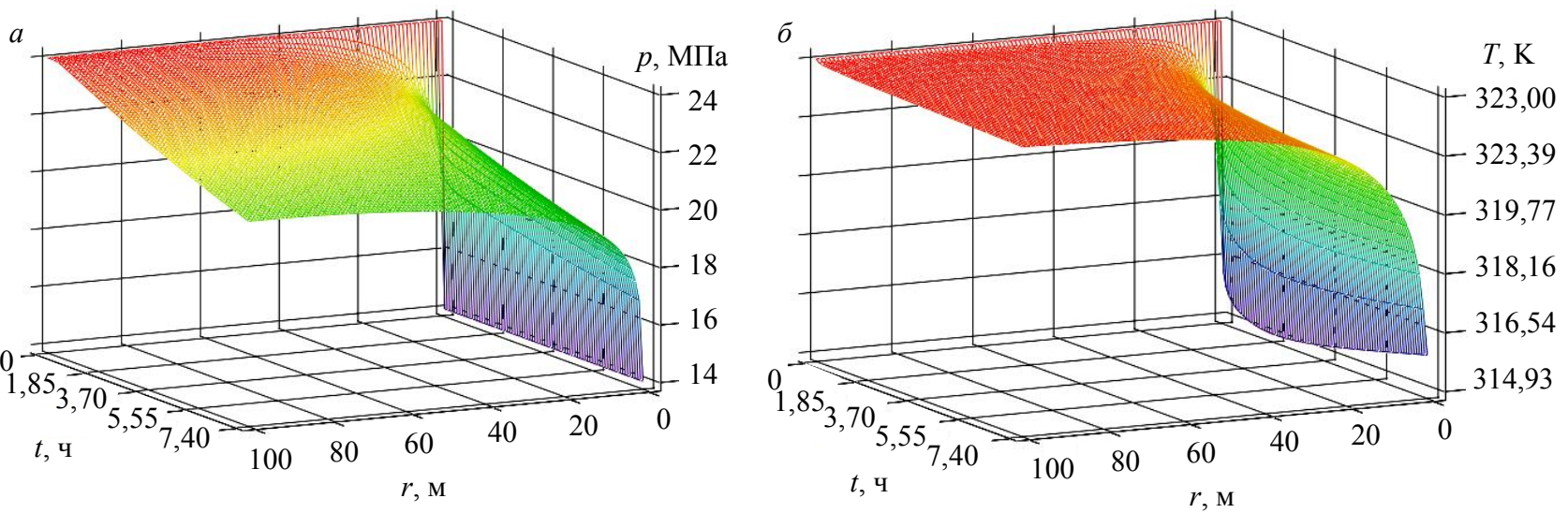

Рис.2. Динамика распределения давления (a) и температуры (б) в пласте для Средневилюйского месторождения

$i \mathrm{C}_{5} \mathrm{H}_{12} 0,12 ; n \mathrm{C}_{5} \mathrm{H}_{12} 0,17 ; \mathrm{C}_{6} \mathrm{H}_{14} 0,17 ; \mathrm{C}_{7} \mathrm{H}_{16+} 0,28 ; \mathrm{CO}_{2} 0,07 ; \mathrm{N}_{2} 9,50 ; \mathrm{H}_{2} 0,02 ;$ Не 0,21; плотность газа по воздуху $-0,685$.

Видно, что при примерно равной глубине продуктивного горизонта состав природного газа, а также пластовые условия этих месторождений существенно различны. Температура гидратообразования, вычисленная по формуле $T_{\mathrm{h}}(p)=a \ln (p)+b$, при заданных забойных давлениях составляет для Средневилюйского и Отраднинского месторождений соответственно 293,6 и 293,4 К. Таким образом во втором случае отбор газа будет сопровождаться образованием гидратов в призабойной зоне, так как начальная температура пласта ниже равновесной температуры гидратообразования. Отметим также, что для указанных значений относительной плотности газов поправочный коэффициент к формулам (2) и (3) равен 0,99, т.е. его можно не учитывать в последующих расчетах.

Анализ результатов вычислений начнем со Средневилюйского месторождения. Предварительно заметим, что для указанных значений входных данных длительность переходных процессов изменения давления и температуры составляет несколько часов, поэтому здесь приводятся результаты расчетов, соответствующих этому периоду. На рис.2 представлены зависимости температуры и давления газа от времени и радиальной координаты.

Эти данные были использованы для вычисления аналогичной зависимости влагосодержания газа по формуле

$$
w(r, t)=\frac{W(p, T)}{\rho(p, T)},
$$

где $\rho$ - плотность газа.

Результаты вычислений представлены на рис.3. Видно, что весовая доля паров воды в газе очень невелика, а форма поверхности $w(r, t)$ практически идентична поверхности $T(r, t)$. Следовательно, в случае контакта газа с водой его влагосодержание в основном определяется характером изменения температуры. Однако не следует забывать, что эти изменения зависят от интенсивности отбора газа, т.е. от изменения давления, от которого, в свою очередь, зависят и интенсивность конвективного переноса тепла, и степень охлаждения газа за счет дросселирования.

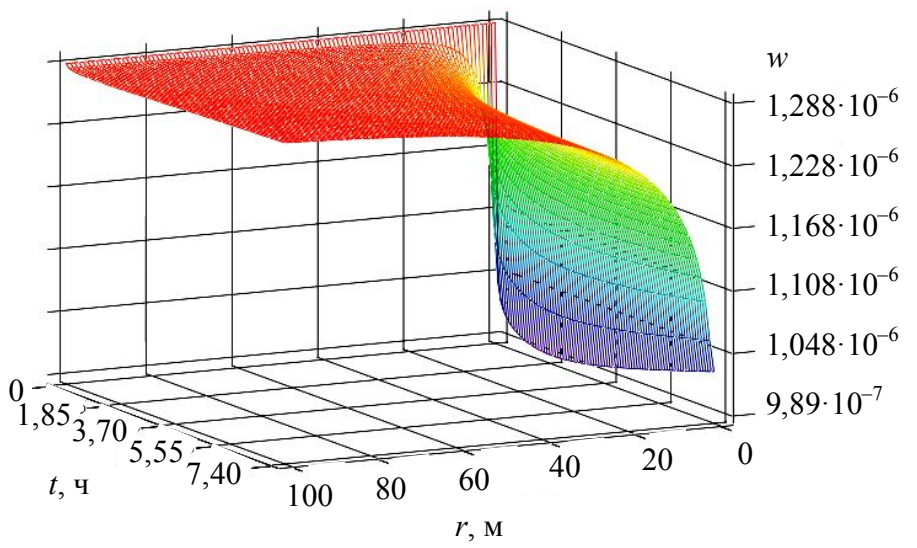

Рис.3. Динамика распределения влагосодержания газа в пласте для Средневилюйского месторождения 

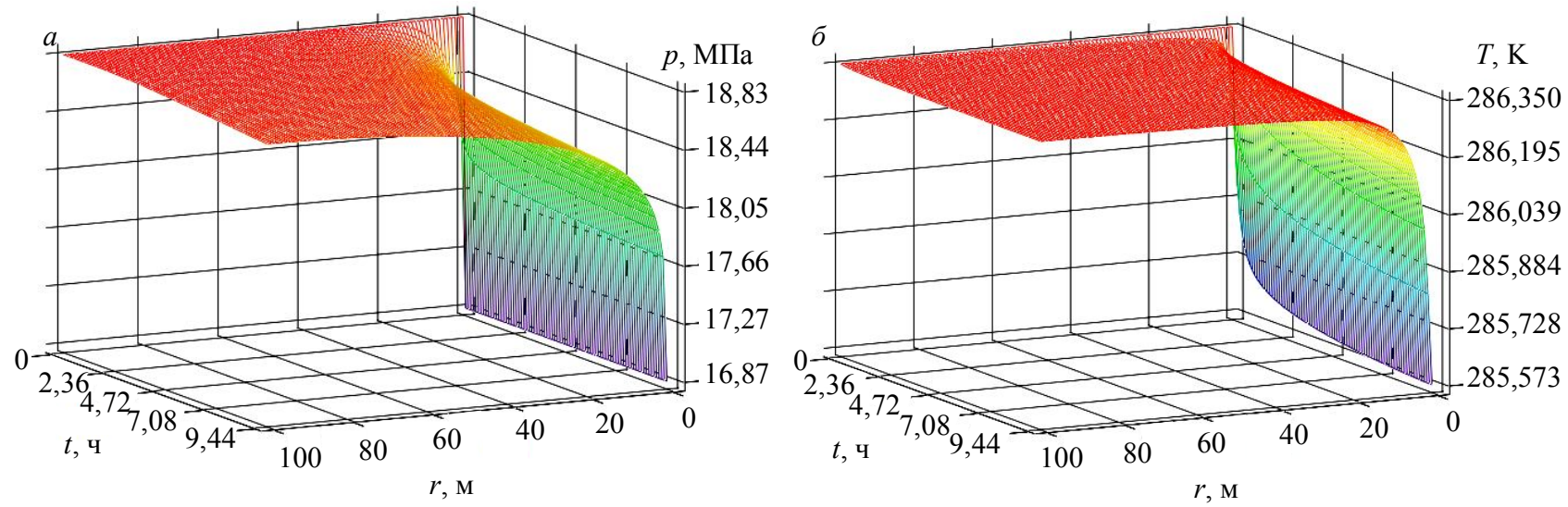

Рис.4. Динамика распределения давления ( $а$ ) и температуры (б) в пласте для Отраднинского месторождения

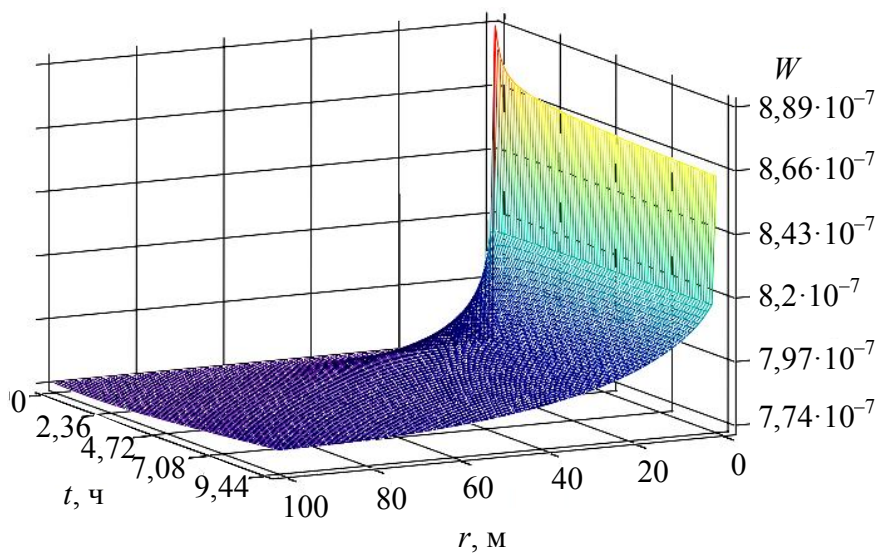

Рис.5. Динамика распределения влагосодержания газа в пласте для Отраднинского месторождения

Соответствующий анализ для Отраднинского месторождения дал следующие результаты. Здесь начальная температура газа ниже равновесной температуры образования гидратов. Следовательно, в формуле (3) выражение для давления водяных паров над чистой водой следует заменить на формулу (4), определяющую давление паров воды над гидратом. В этом случае, несмотря на качественное сходство зависимостей давления и температуры от координаты и времени с предыдущим примером (рис.4), форма поверхности $w(r, t)$ существенно иная, а весовая доля влаги в газе близка по величине к предыдущему результату только в непосредственной близости от забоя скважины, а затем резко уменьшается почти до нуля (рис.5).

Заключение. В вычислительном эксперименте показано, что если пластовая температура существенно превышает равновесную температуру гидратообразования, то распределение влагосодержания в призабойной зоне будет практически идентично распределению температуры. В противном случае газ будет содержать пары воды только вблизи забоя скважины, а далее влагосодержание будет практически равно нулю. Роль давления и в том и в другом случаях проявляется через интенсивность отбора газа, от которого, в свою очередь, зависят и интенсивность конвективного переноса тепла, и степень охлаждения газа за счет дросселирования.

Благодарность. Работа выполнена в рамках Госзаказа ФАНО РФ (проект № IX.131.4.5, номер ФАНО 0377-2016-0003).

\section{ЛИТЕРАТУРА}

1. Бондарев Э.А. Особенности математического моделирования систем добычи и транспорта природного газа в Арктической зоне России / Э.А.Бондарев, И.И.Рожин, К.К.Аргунова // Записки Горного института. 2017. Т. 228. С. 705-716. DOI: 10.25515/PMI.2017.6.705.

2. Бондарев Э.А. Плоскопараллельная неизотермическая фильтрация газа: роль теплопереноса / Э.А.Бондарев, К.К.Аргунова, И.И.Рожин // Инженерно-физический журнал. 2009. Т. 82. № 6. С. 1059-1065.

3. Брусиловский А.И. Фазовые превращения при разработке месторождений нефти и газа. М.: Грааль, 2002.575 с.

4. Гухман Л.М. Подготовка газа северных газовых месторождений к дальнему транспорту. Л.: Недра, 1980. 161 с.

5. Дегтярев Б.В. Борьба с гидратами при эксплуатации газовых скважин в северных районах / Б.В.Дегтярев, Э.Б.Бухгалтер. М.: Недра, 1976. 197 с.

6. Истомин В.А. Предупреждение и ликвидация газовых гидратов в системах добычи газа / В.А.Истомин, В.Г.Квон. М.: ООО «ИРЦ Газпром», 2004. $506 \mathrm{c.}$ 
7. Коротаев Ю.П. Борьба с гидратами при транспорте природных газов / Ю.П.Коротаев, А.М.Кулиев, Р.М.Мусаев. М.: Недра, 1973. $136 \mathrm{c}$.

8. Латонов В.В. Расчет коэффициента сжимаемости природных газов / В.В.Латонов, Г.Р.Гуревич // Газовая промышленность. 1969. № 2. С. 7-9.

9. Намиот А.Ю. Растворимость газов в воде: Справочное пособие. М.: Недра, 1991. 167 с.

10. Николаев B.E. Численный анализ взаимодействия тепловых и гидродинамических процессов при фильтрации газа: Автореф. ... канд. физ.-мат. наук / Якутский государственный университет им. М.К.Аммосова. Якутск, 2000. 13 с.

11. Термогидродинамика систем добычи и транспорта газа / Э.А.Бондарев, В.И.Васильев, А.Ф.Воеводин, Н.Н. Павлов, А.П.Шадрина. Новосибирск: Наука. Сибирское отделение, 1988. 272 с.

12. Bondarev E.A. Plane-parallel nonisothermal gas filtration: the role of thermodynamics / E.A.Bondarev, K.K.Argunova, I.I.Rozhin // Journal of Engineering Thermophysics. 2009. Vol. 18. № 2. P. 168-176. DOI: 10.1134/S1810232809020088.

13. Bukacek R.F. Equilibrium moisture content of natural gases // Research Bulletin. Institute of Gas Technology, Chicago, USA. 1955. Vol. 8. № 11. P. 20.

14. Kay W.B. Density of hydrocarbon gases and vapors at high temperature and pressures // Industrial \& Engineering Chemistry Research. 1936. Vol. 28. P. 1014-1019.

15. Sloan E.D. Clathrate hydrates of natural gases / E.D.Sloan, C.A.Koh. Boca Raton: Taylor \& Francis Group/CRC Press, 2008. $720 \mathrm{p}$.

Авторы: Э.А. Бондарев, д-р техн. наук, главный научный сотрудник, bondarev@ipng.ysn.ru (ФГБУН «Институт проблем нефти и газа Сибирского отделения РАН», Якутск, Россия), И.И. Рожин, д-р техн. наук, ведущий научный сотрудник,__rozhin@mail.ru (ФГБУН «Институт проблем нефти и газа Сибирского отделения РАН», Якутск, Россия), К.К. Аргунова, канд. физ.-мат. наук, старший научный сотрудник, akk@ipng.ysn.ru (ФГБУН «Институт проблем нефти и газа Сибирского отделения РАН», Якутск, Россия).

Статья поступила в редакиию 11.02.2018.

Статья принята к публикаичи 08.05.2018. 